\title{
COMPARISON BETWEEN TWO TYPES OF WINEMAKING TANKS FOR THE PRODUCTION OF QUALITY WINES CV. NERO D'AVOLA
}

\author{
Pietro Catania, Felice Pipitone, Mariangela Vallone
}

\section{Introduction}

Among the many factors that influence the quality of wines produced from black grapes, an important role is played by the polyphenolic compounds that determine specific sensory characteristics, including colour and flavour [Somers 1971; Arnold 1980], and stabilize wines against oxidation [Rice-Evans 1997; Di Majo 2008].

Polyphenols do not only characterize the sensory profile of a red wine as they also possess antioxidant properties, vitamins and protection toward cardiovascular disease [Rakotovao 2004; Ribéreau-Gayon 1998; Ruf 2003]. Cultivar, climatic conditions, time of harvest and systems technology adopted for winemaking, particularly during maceration and fermentation, are the main aspects that determine their concentrations in wine.

The colour of red wine, as an important quality parameter, is determined mainly by the quantity and composition of anthocyanins present in black grapes. They define the wine's palatability and astringency, together with tannins.

All the black grape berry varieties have a distinctive profile of anthocyanins and tannins that, among other factors, determine the sensory characteristics of wine and their evolution during aging.

During this period, the phenomena of polymerization of tannins and condensation between anthocyanins and tannins, lead to the production of phenolic compounds with a higher molecular weight, which contribute to stabilize the color of wine [RibéreauGayon 1998; Pérez-Lamela 2007; Gomez-Plaza 2002; Castillo-Sanchez 2008], improve the sensory characteristics and enhance the antioxidant effect [Rice-

Paper received 06.08.2010; accepted 15.02.2011

Pietro Catania, associate professor; Felice Pipitone, full professor, MARIANGEla VALlone, researcher; Department of Agro-Environmental Systems - University of Palermo, Viale delle Scienze ed.4 90128 Palermo, Italy. E-mail: p.catania@unipa.it, tel. +39 91 23865608 , fax +39 91484035 .

The authors have contributed equally to the work.
Evans 1997; Netzel 2003; Echeverry 2005].

Another important factor to take into account because of the role played by wine colour is the systems technology adopted and in particular the type of winemaking tank.

Fermentation tanks have evolved considerably over the last year. Today the choice of a wine fermenter can be oriented towards three typologies: vertical winemaking, rotary horizontal winemaking and horizontal winemaking tank with rotating blades inside.

Winemaking experiences performed with rotary horizontal winemaking tanks [Gigliotti 1980; Rieger 1999] showed a $100 \%$ increase in total anthocyanins, a $54 \%$ increase in colour intensity and a $45 \%$ increase in total polyphenols respect to the wines coming from traditional winemaking.

Among the varieties of wine grapes cultivated in Sicily, Nero d'Avola is one of the most important for the production of wines of quality. The interest in this cultivar has been encouraged by the high concentration of resveratrol in wines made from it [Amirante 2004].

It also presents a good aromatic complex [Corona and Asproudi 2003] with several terpenic notes that give the wine particular aromas such as a fruity, floral scent of berries. Some aromas complementing each other determine the wine a distinct native characterization, very important for its typicality.

The aim of this work is to compare two types of winemaking tanks, horizontal and vertical, using Nero $\mathrm{d}$ 'Avola grapes, in order to assess the capacity of extracting phenolic compounds that determine the quality of red wines.

\section{Materials and methods}

The tests were carried out in 2008 in a cellar located in Marsala (Sicily, Italy). The grapes, cultivar Nero d'Avola, were manually harvested, they were placed into boxes and transported to the cellar. The arrangement in boxes, respecting the integrity of the grapes, and the ambient temperature around $22^{\circ} \mathrm{C}$ helped to limit the inconveniences of the time necessary to 
transfer the harvested grapes from the field to the wine cellar [Catania 2009].

The winemaking process was realized with modern plants, in order to safeguard the characteristics of the raw material processed and the quality of the product. They also allowed a rational and controlled processing of the grapes.

After weighing, operated by a platform balance, each box was individually discharged into the hopper, consisting of a metal partially filled-in tank, and a trapezoidal section, fitted with an Archimedes' screw to feed the destemmer crusher. The destemming was carried out in a soft way to avoid the formation of lees and laceration of the skins, stems and seeds.

Then the berries, not too ripe, were subject to a drain of $10 \%$, which is to decrease the volume of juice in order to increase the impact of phenolic compounds of the solid parts by increasing the contribution of grape skins and seeds in relation to grape juice. A mixture of potassium pyrosulphite and ascorbic acid $(0.2 \mathrm{~g} / \mathrm{kg})$ and the Saccharomyces cerevisiae yeasts $(0.3 \mathrm{~g} / \mathrm{kg})$ were added to the crushed grapes.

Then, the destemmed and crushed grapes were sent to two different winemaking tanks: a horizontal (model VMO) and a vertical one (model SPV) by Velo Company.

Hereafter, the test regarding the horizontal tank is named "test 1 " and the test regarding the vertical one is named "test 2 ".

In the horizontal fermenter, consisting of a stainless steel (AISI 304) cylindrical, horizontal and insulated tank, having capacity of $100 \mathrm{hl}$, the shaking of the must with the consequent breaking of the marc cap, is obtained through a counterclockwise rotation of special articulated blades. Rotation of the blades is ensured by a gear motor with an inverter controlled by an electric panel that enables to adjust speed, frequency and the duration of rotation, allowing to properly intervene during the fermentation process. Marc evacuation is guaranteed by a system of mechanical arms ending with silicone food terminals rotating in opposition to the agitation, that drive skins and seeds towards the total discharge hatch without damaging them.

Even the vertical fermenter is entirely made of stainless steel AISI 304 and has a capacity of $100 \mathrm{hl}$; it has an inclined flat bottom, a rectangular hatch for the discharge of the marc and jacket to control temperature. During the pumping-over, must flow is projected onto a rotating metal plate which makes a uniform distribution on the marc cap.

Before the maceration started, the main quality parameters of the grape must were determined: sugars $193.50 \mathrm{~g} / \mathrm{L}, \mathrm{pH} 3.17$, total acidity $8.64 \mathrm{~g} / \mathrm{L}$ and total polyphenols with an index of 54 .

During maceration chemical analyses of the mustwines and the choices regarding the duration and number of the must pumping-over for the two winemaking tanks were performed daily. In particular, the management of pumping-over was carried out according to data provided by the laboratory and the state of disintegration of the skins. On the fourth day of the winemaking process activators were added in both fermenters, $0.2 \mathrm{~g} / \mathrm{kg}$ Aromax including thiamine $(0.06 \%)$, tannins $(12 \%)$, yeast $(48 \%)$ and diammonium hydrogen phosphate (about $40 \%$ ).

Table 1 shows data of the pumping-over performed in the two winemaking tanks: duration, interval between two cycles, temperature and the speed of the horizontal winemaking tank blades.

The maceration lasted 180 hours (approximately 8 days) in the two winemakers.

The maceration temperature is undoubtedly one of the basic parameters that affect the process itself. It depends on many factors such as temperature of the grapes arriving in the cellar, cellar temperature and its aeration and humidity, calories produced during the alcoholic fermentation and their rapid growth, shape, volume and insulation of the tanks for fermentation and maceration, pumping-over cycles, etc. [De Rosa 1983].

The temperature recorded during the winemaking process in the two tests was that produced naturally during the maceration. Therefore, the different temperatures verified in the two tests can be attributed to the different construction characteristics of the winemakers.

In the horizontal winemaker the replacements consisted in the counter clockwise rotation of the articulated blades, played in the eight days of maceration at

\begin{tabular}{cccccccc}
\hline & \multicolumn{3}{c}{ Horizontal winemaking tank } & \multicolumn{3}{c}{ Vertical winemaking tank } \\
\hline Day & $\begin{array}{c}\text { Time } \\
{[\mathrm{min}]}\end{array}$ & $\begin{array}{c}\text { Temperature } \\
{\left[{ }^{\circ} \mathrm{C}\right]}\end{array}$ & $\begin{array}{c}\text { Interval } \\
{[\mathrm{h}]}\end{array}$ & $\begin{array}{c}\text { Blades speed } \\
{[\mathrm{r} / \mathrm{min}]}\end{array}$ & $\begin{array}{c}\text { Time } \\
{[\mathrm{min}]}\end{array}$ & $\begin{array}{c}\text { Temperature } \\
{\left[{ }^{\circ} \mathrm{C}\right]}\end{array}$ & $\begin{array}{c}\text { Interval } \\
{[\mathrm{h}]}\end{array}$ \\
\hline 1 & 10 & 21 & 3 & 0.7 & 6 & 24 & 6 \\
2 & 10 & 27 & 3 & 0.7 & 6 & 28 & 6 \\
3 & 8 & 24 & 4 & 0.5 & 6 & 28 & 6 \\
4 & 8 & 22 & 6 & 0.5 & 6 & 27 & 6 \\
5 & 10 & 22 & 8 & 0.3 & 6 & 6 & 6 \\
6 & 10 & 27 & 10 & 0.3 & 6 & 22 & 6 \\
7 & 10 & 26 & 10 & 0.3 & 6 & 6 & 6 \\
8 & 10 & 24 & 10 & 0.3 & 6 & 21 & 6 \\
\hline
\end{tabular}

TABLE 1 - Pumping-over cycles during maceration in the two winemaking tanks. 
different times, range and speed. In particular, the period of replacement was almost always 10 minutes except on days 3 and 4 which was equal to $8 \mathrm{~min}$, the interval of execution was every 3 hours during the first two days, every 4, 6 and 8 hours respectively in the third, fourth and fifth day and then every 10 hours over the last three days. Regarding the rotation speed of the blades, it was higher in the first two days (0.7 $\mathrm{r} / \mathrm{min}$ ), slightly lower than the third and fourth day $(0.5 \mathrm{r} / \mathrm{min})$ and very low in the last three days $(0.3$ $\mathrm{r} / \mathrm{min})$.

At the end of maceration, both in the horizontal and in the vertical winemaking tanks, the racking was performed, whose product, consisting of wine and grape skins, was sent to the pneumatic press for a soft pressing. The operating pressures were the same for both the tests: $0.3 \mathrm{~atm}$ for about 2 hours in the initial phase and $0.8-1.2-1.6$ atm at later stages for a time of 16 min each.

The wine obtained from the two tests was kept separately in two tanks having capacity of $75 \mathrm{hl}$.

In order to verify the quality of wine made from the two types of fermenters, consisting in the study of the degree of polymerization of polyphenols, the determination of the main quality parameters was performed.

In particular, during the maceration process, 180 hours long, divided into intervals of 24 hours, named from $\mathrm{T} 1$ to $\mathrm{T} 8$, the following parameters were assessed: sugars $(\mathrm{g} / \mathrm{L})$, anthocyanins $(\mathrm{mg} / \mathrm{L})$, total polyphenols index $(\mathrm{TPI})$, volatile acidity $(\mathrm{g} / \mathrm{L})$, colour intensity and hue.

In the post-fermentation, namely from the end of the alcoholic and malolactic fermentation, named T0', for four months, the following parameters were monthly assessed: $\mathrm{pH}$, free and total sulfur dioxide $(\mathrm{mg} / \mathrm{L})$, total anthocyanins $(\mathrm{mg} / \mathrm{L})$, monomers anthocyanins $(\mathrm{mg} / \mathrm{L})$, decomposition of the absorbance at $420 \mathrm{~nm}, 520 \mathrm{~nm}$ and $620 \mathrm{~nm}$ of the wine, total flavonoids $(\mathrm{mg} / \mathrm{L})$, proanthocyanidins $(\mathrm{mg} / \mathrm{L})$ and acetaldehyde $(\mathrm{mg} / \mathrm{L})$. The tests monthly performed were respectively named $\mathrm{T} 1$ ', $\mathrm{T} 2$ ', $\mathrm{T} 3$ ' and $\mathrm{T} 4$ '.

The colour intensity values were obtained adding absorbance at $420 \mathrm{~nm}$ (yellow due to tannins) and 520 $\mathrm{nm}$ (red due to anthocyanins), while hue as the ratio of the absorbance at $420 \mathrm{~nm}$ and $520 \mathrm{~nm}$.

The determination of colour intensity and hue were done according to Ribéreau-Gayon et al. 1998; the assessment of total polyphenols was carried out following the Ribéreau-Gayon methodology, 1998. Total anthocyanins, total flavonoids and monomers anthocyanins were determined according to Di Stefano et al. 1989. The other determinations were performed as provided by the official methods of analysis according to EC Regulation 2676/90.

Triplicate analyses for each determination were carried out. The data obtained were subject to statistical analysis and the means of the two tests compared by t-test at a $95 \%$ confidence level using the software Statgraphics Centurion Statpoint inc., USA.

\section{Results and discussion}

Table 2 shows the values of the qualitative parameters of the two tests, evaluated during the maceration process.

It emerges that the values of sugars undergo a higher decrease in test 1 till stage T4 in which the values appear to be similar in the two tests till the end of winemaking process. Statistically significant differences in the mean values of sugars were found, in fact, between the two tests until that stage.

Regarding anthocyanins, there is always a greater extraction in test 1 with statistically significant differences compared to test 2 . Test 1 presents an ever greater extraction of anthocyanins than test 2 , namely $28 \%$ in stage $\mathrm{T} 1,40 \%$ in $\mathrm{T} 2,43 \%$ in $\mathrm{T} 3,30 \%$ in $\mathrm{T} 4$, $19 \%$ in $\mathrm{T} 5,27 \%$ in $\mathrm{T} 6,15 \%$ in $\mathrm{T} 7$ and $19 \%$ in $\mathrm{T} 8$.

The extraction of anthocyanins was very rapid at the initial stage of maceration; an important result was reached in test 1 in T2 stage $(631.15 \mathrm{mg} / \mathrm{L})$. The maximum content of anthocyanins was reached in both the tests in T6 stage, with values of $736.34 \mathrm{mg} / \mathrm{L}$ in test 1 and $608.76 \mathrm{mg} / \mathrm{L}$ in test 2 . A decrease of anthocyanins until racking is observed in both the tests after T6 stage.

The extraction of total polyphenols is always higher in test 1 , reaching a maximum concentration after the stage of maceration named T6. At the end of fermentation the total polyphenols concentration in test 1 is about $20 \%$ higher than test 2 with statistically significant differences at a $95 \%$ confidence level.

The maceration temperature has undoubtedly played a key role with higher values for test 1 than test 2 in the final stages of maceration; together with a high concentration of alcohol, it has positively influenced the polyphenolic substance extraction process.

The volatile acidity during fermentation stood on values always lower than $0.2 \mathrm{~g} / \mathrm{L}$ in both the tests.

Concerning the colour hue, it was greater in the vertical winemaker with statistically significant differences only in wine samples taken at stages T3 and $\mathrm{T} 4$. At the end of fermentation the hue values are similar in the two tests.

The colour intensity values of wines show a very similar trend in the two tests always being higher in test 1 than test 2 , with statistically significant differences in wine samples taken at stages T2, T3, T4 and T8. As a consequence, test 1 shows a higher efficiency in the extraction of anthocyanins in the early days of maceration.

In Table 3 the mean values of the main quality parameters of the two tests are shown. The $\mathrm{pH}$ wine ranged between 3.21 and 3.48 throughout the study period during aging, with no statistically significant difference at the $95 \%$ confidence level between the mean values of the two tests.

Also the free $\mathrm{SO}_{2}$ values, going from 13.0 to 30.0 $\mathrm{mg} / \mathrm{L}$ throughout the observation period, showed no statistically significant differences at the $95 \%$ confidence level. 


\begin{tabular}{|c|c|c|c|c|c|c|c|c|c|c|c|c|c|c|c|c|}
\hline & \multicolumn{2}{|c|}{ T1 } & \multicolumn{2}{|c|}{ T2 } & \multicolumn{2}{|c|}{ T3 } & \multicolumn{2}{|c|}{ T4 } & \multicolumn{2}{|c|}{ T5 } & \multicolumn{2}{|c|}{ T6 } & \multicolumn{2}{|c|}{ T7 } & \multicolumn{2}{|c|}{ T8 } \\
\hline & Test 1 & Test 2 & Test 1 & Test 2 & Test 1 & Test 2 & Test 1 & Test 2 & Test 1 & Test 2 & Test 1 & Test 2 & Test 1 & Test 2 & Test 1 & Test 2 \\
\hline Sugars $[\mathrm{g} / \mathrm{L}]$ & $170.24 \pm 3.34$ & $180.70 \pm 1.04 *$ & $89.95 \pm 1.92$ & $103.00 \pm 1.61^{*}$ & $26.41 \pm 1.38$ & $46.00 \pm 1.33^{*}$ & $1.47 \pm 0.16$ & $1.20 \pm 0.14$ & $1.30 \pm 0.03$ & $1.68 \pm 0.06 *$ & $1.74 \pm 0.07$ & $1.59 \pm 0.20$ & $1.62 \pm 0.17$ & $1.70 \pm 0.11$ & $1.50 \pm 0.22$ & $1.80 \pm 0.16$ \\
\hline Anthocyanins $[\mathrm{mg} / \mathrm{L}]$ & $101.09 \pm 2.90$ & $72.50 \pm 3.23^{*}$ & $631.15 \pm 7.69$ & $381.67 \pm 5.97^{*}$ & $621.58 \pm 3.49$ & $352.94 \pm 2.42 *$ & $691.26 \pm 2.18$ & $485.64 \pm 3.41 *$ & $699.45 \pm 6.17$ & $570.45 \pm 3.24 *$ & $736.34 \pm 4.93$ & $608.76 \pm 4.50$ & $614.75 \pm 2.03$ & $525.31 \pm 2.10^{*}$ & $532.79 \pm 1.95$ & $433.65 \pm 3.11^{*}$ \\
\hline TPI & $21.10 \pm 1.19$ & $18.10 \pm 0.95^{*}$ & $41.30 \pm 1.07$ & $29.00 \pm 2.59^{*}$ & $37.10 \pm 1.42$ & $29.00 \pm 0.94 *$ & $44.70 \pm 2.44$ & $35.50 \pm 1.75^{*}$ & $48.00 \pm 2.31$ & $39.20 \pm 1.82^{*}$ & $53.20 \pm 0.90$ & $43.10 \pm 2.54 *$ & $46.30 \pm 1.73$ & $38.70 \pm 1.57 *$ & $46.60 \pm 3.04$ & $37.40 \pm 1.73^{*}$ \\
\hline Volatile acidity $[\mathrm{g} / \mathrm{L}]$ & $0.11 \pm 0.02$ & $0.10 \pm 0.03$ & $0.14 \pm 0.02$ & $0.12 \pm 0.04$ & $0.19 \pm 0.07$ & $0.14 \pm 0.04 *$ & $0.10 \pm 0.02$ & $0.14 \pm 0.02 *$ & $0.18 \pm 0.03$ & $0.10 \pm 0.01$ * & $0.12 \pm 0.03$ & $0.22 \pm 0.05^{*}$ & $0.17 \pm 0.04$ & $0.19 \pm 0.03$ & $0.19 \pm 0.04$ & $0.19 \pm 0.07$ \\
\hline Hue & $0.40 \pm 0.05$ & $0.45 \pm 0.04$ & $0.45 \pm 0.05$ & $0.55 \pm 0.07$ & $0.47 \pm 0.05$ & $0.70 \pm 0.10^{*}$ & $0.44 \pm 0.05$ & $0.58 \pm 0.07^{*}$ & $0.48 \pm 0.08$ & $0.56 \pm 0.10$ & $0.48 \pm 0.06$ & $0.58 \pm 0.04$ & $0.52 \pm 0.03$ & $0.60 \pm 0.14$ & $0.56 \pm 0.05$ & $0.65 \pm 0.04$ \\
\hline Colour intensity & $8.50 \pm 0.93$ & $6.50 \pm 1.26$ & $9.50 \pm 0.70$ & $7.11 \pm 0.95 *$ & $10.25 \pm 1.25$ & $7.34 \pm 0.34$ * & $10.81 \pm 1.10$ & $8.40 \pm 0.71 *$ & $11.82 \pm 1.41$ & $9.65 \pm 0.69$ & $11.84 \pm 1.24$ & $9.86 \pm 0.43$ & $11.26 \pm 1.06$ & $9.74 \pm 0.34$ & $11.50 \pm 0.64$ & $9.90 \pm 0.39 *$ \\
\hline
\end{tabular}

TABLE $\quad 2$ - Results of the analyses performed during the maceration process.

Note: data are reported as means \pm standard deviations of the three determinations. $*$ in the row denotes statistically significant differences between test 1 and test 2 at the $95.0 \%$ confidence level.

\begin{tabular}{|c|c|c|c|c|c|c|c|c|c|c|}
\hline \multirow[t]{2}{*}{ Post-fermentation stage } & \multicolumn{2}{|c|}{ T0' } & \multicolumn{2}{|c|}{ T1 } & \multicolumn{2}{|c|}{$\mathbf{T} 2$} & \multicolumn{2}{|c|}{ T3' } & \multicolumn{2}{|c|}{ T4' } \\
\hline & Test 1 & Test 2 & Test 1 & Test 2 & Test 1 & Test 2 & Test 1 & Test 2 & Test 1 & Test 2 \\
\hline $\mathrm{pH}$ & $3.21 \pm 0.70$ & $3.29 \pm 0.54$ & $3.35 \pm 0.60$ & $3.41 \pm 0.47$ & $3.36 \pm 0.46$ & $3.43 \pm 0.65$ & $3.36 \pm 0.35$ & $3.44 \pm 0.57$ & $3.39 \pm 0.34$ & $3.48 \pm 0.52$ \\
\hline Free $\mathrm{SO}_{2}[\mathrm{mg} / \mathrm{L}]$ & $13.00 \pm 1.73$ & $13.00 \pm 1.00$ & $35.00 \pm 3.00$ & $35.00 \pm 1.73$ & $22.40 \pm 2.65$ & $22.40 \pm 1.76$ & $25.00 \pm 1.00$ & $25.00 \pm 2.65$ & $26.00 \pm 2.00$ & $30.00 \pm 2.00$ \\
\hline Total $\mathrm{SO}_{2}[\mathrm{mg} / \mathrm{L}]$ & $54.00 \pm 1.73$ & $32.00 \pm 2.65^{*}$ & $93.00 \pm 2.00$ & $61.00 \pm 1.00^{*}$ & $70.40 \pm 1.59$ & $56.30 \pm 2.13^{*}$ & $88.00 \pm 1.75$ & $68.00 \pm 2.65^{*}$ & $84.00 \pm 3.61$ & $58.00 \pm 2.65^{*}$ \\
\hline Total anthocyanins $[\mathrm{mg} / \mathrm{L}])$ & $533 \pm 12.12$ & $433 \pm 12.12 *$ & $482 \pm 7.21$ & $387 \pm 9.17^{*}$ & $436 \pm 5.57$ & $359 \pm 8.08^{*}$ & $394 \pm 10.79$ & $332 \pm 7.51^{*}$ & $379 \pm 6.24$ & $323 \pm 10.02 *$ \\
\hline Monomers anthocyanins [mg/L] & $392 \pm 8.89$ & $313 \pm 10.52^{*}$ & $338 \pm 12.53$ & $262 \pm 8.54^{*}$ & $301 \pm 7.23$ & $244 \pm 11.53^{*}$ & $265 \pm 10.54$ & $225 \pm 5.57^{*}$ & $260 \pm 8.72$ & $203 \pm 5.69^{*}$ \\
\hline $\mathrm{E}_{420,1 \mathrm{~mm}}$ & $3.96 \pm 0.17$ & $3.70 \pm 0.11$ & $3.76 \pm 0.17$ & $3.55 \pm 0.16$ & $3.66 \pm 0.15$ & $3.14 \pm 0.06$ & $3.09 \pm 0.07$ & $2.93 \pm 0.15$ & $3.05 \pm 0.11$ & $2.79 \pm 0.10$ \\
\hline $\mathrm{E}_{520,1 \mathrm{~mm}}$ & $6.60 \pm 0.09$ & $5.60 \pm 0.17^{*}$ & $6.26 \pm 0.15$ & $5.55 \pm 0.11^{*}$ & $5.54 \pm 0.15$ & $4.36 \pm 0.15^{*}$ & $4.11 \pm 0.08$ & $3.57 \pm 0.14^{*}$ & $3.95 \pm 0.08$ & $3.41 \pm 0.08^{*}$ \\
\hline $\mathrm{E}_{620,1 \mathrm{~mm}}$ & $0.245 \pm 0.049$ & $0.188 \pm 0.009$ & $0.158 \pm 0.009$ & $0.143 \pm 0.010$ & $0.153 \pm 0.08$ & $0.127 \pm 0.003 *$ & $0.122 \pm 0.002$ & $0.108 \pm 0.05 *$ & $0.104 \pm 0.003$ & $0.092 \pm 0.002 *$ \\
\hline $\mathrm{E}_{420} / \mathrm{E}_{520}$ & 0.60 & 0.66 & 0.60 & 0.64 & 0.66 & 0.72 & 0.75 & 0.82 & 0.77 & 0.82 \\
\hline$\left(\mathrm{E}_{420}+\mathrm{E}_{520}\right)_{1 \mathrm{~mm}}$ & 10.56 & 9.30 & 10.02 & 9.10 & 9.20 & 7.50 & 7.20 & 6.50 & 7.00 & 6.20 \\
\hline
\end{tabular}

TABLE 3 - Results of the post-fermentation analyses.

Note: data are reported as means \pm standard deviations of the three determinations. * in the row denotes statistically significant differences between test 1 and test 2 at the $95.0 \%$ confidence level. 
On the contrary, as regards the average values of total $\mathrm{SO}_{2}$, there were statistically significant differences at all stages, from T0' to T4', with values higher in test 1 than test 2 on the average of $32 \%$.

Even the mean values of total anthocyanins always show statistically significant differences throughout the study period between the two tests, with test 1 always higher than test 2 , namely $19 \%$ in $\mathrm{T} 1$ ', $20 \%$ in T2', $18 \%$ in T3' and $15 \%$ in T4'. Note, in particular, as the reduction of the values from T0' to T4' is more pronounced in test $1(-29 \%)$ compared to test 2 ($25 \%)$.

Regarding the decomposition of the absorbance at $420 \mathrm{~nm}, 520 \mathrm{~nm}$ and $620 \mathrm{~nm}$ of wine, statistically significant differences were obtained between the two tests throughout the experimental period in absorbance at $520 \mathrm{~nm}$, with values of test 1 always higher than test 2 on average of $15 \%$.

The values of colour intensity gave statistically significant differences between the two tests in stages T0' and T2', with higher values in test 1 than in test 2 respectively by $12 \%$ and $19 \%$.

The hue values showed no statistically significant differences between the two tests in all the stages.

In figure 1 the values of total flavonoids obtained in the two tests in the different stages are represented.

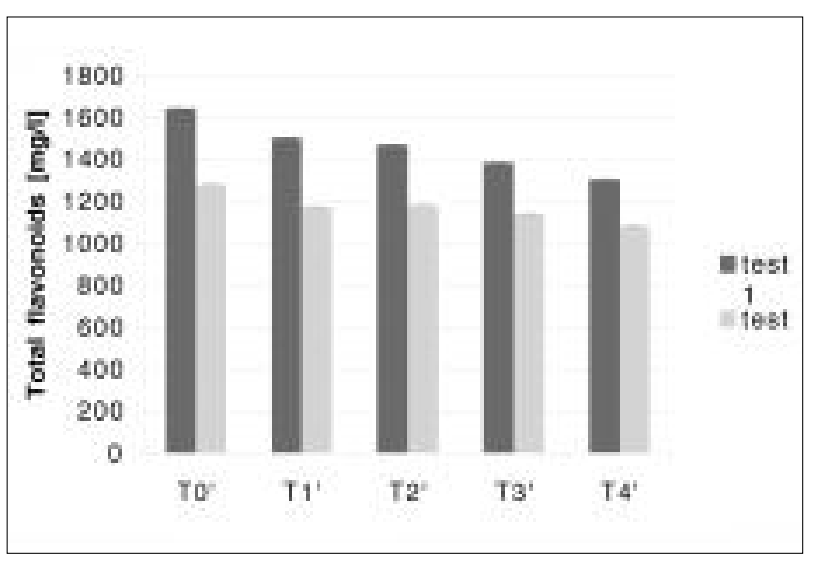

Fig. 1 - Total flavonoids obtained in the two tests in the different stages.

It shows that total flavonoids, essential for the structure of the future wine, in all the stages are higher in test 1 than test 2 onaverage by $20 \%$, with statistically significant differences between the two tests.

Also the content in proanthocyanidins (Fig. 2), molecules with therapeutic properties, is always higher in test 1 than test 2 in all the stages on average by $26 \%$ with statistically significant differences between the two tests. Also note that the decrease of proanthocyanidins from T0' to T4' is more evident in test 1 ($15 \%)$ than test $2(-10 \%)$.

Finally, the values of acetaldehyde (Fig. 3), also higher on average by $39 \%$ in test 1 than test 2 , showed statistically significant differences in all the stages.

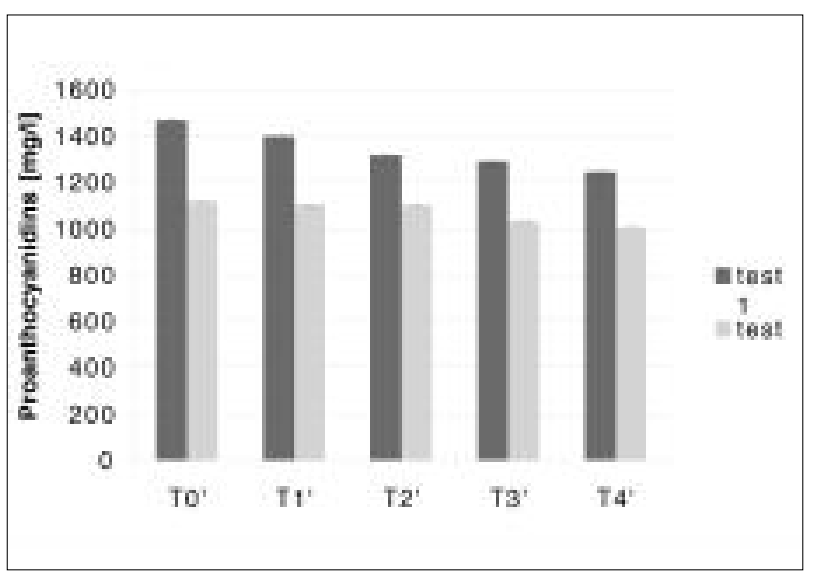

Fig. 2 - Proanthocyanidins obtained in the two tests in the different stages.

The different values of the main compounds analyzed during the post-fermentation stages in the two tests can be attributed to the different construction characteristics of the winemaking tanks, in particular to the dissimilar methods for implementing the maceration process. These issues, in fact, have certainly affected the temperature values recorded during the maceration, resulting in different kinetics of fermentation in the two tests.

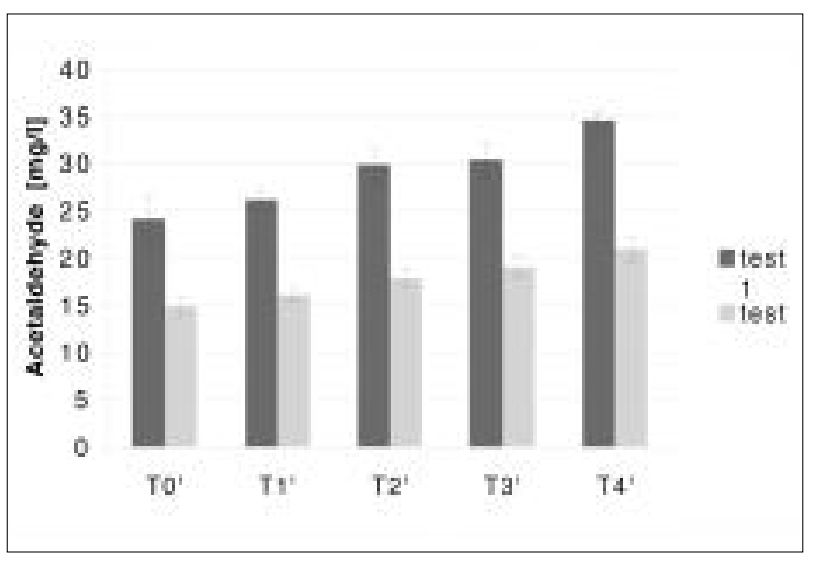

Fig. 3 - Acetaldehyde obtained in the two tests in the different stages.

\section{Conclusions}

The results obtained comparing the two types of winemaking tanks for the production of red wine $\mathrm{cV}$ Nero d'Avola, confirm what other authors concluded for other varieties of wine grapes.

The horizontal winemaking tank has the negative aspect of larger dimensions than the vertical type, that is well known in literature.

However, the results indicate that the horizontal type can produce wines with higher values of both the polyphenolic component and colour in terms of hue and intensity.

Already during the winemaking it was found that anthocyanins of wine made by horizontal winemaking 
tank achieved very high concentration before the vertical type in which there was a slow and steady increase in anthocyanins.

The study also shows that in wine made by horizontal winemaking tanks both anthocyanins and polyphenols have a higher decrease in time compared to wine made by the vertical type, although the largest quantities are found eventually in the first type.

From the above it can be assumed that the use of the horizontal winemaking tank must be optimized to enhance the reactions that lead to increased stability of anthocyanins and, as a consequence, of colour.

The higher values of polyphenols found in the horizontal type appear to show that wines produced by this type of winemaking tank have a better quality in terms of health for antimicrobial, antioxidant and antiinflammatory properties of these molecules.

\section{References}

Amirante P., Pipitone F., Dugo G., Tamborrino A., Leone A., Clodoveo M.L. L'influenza delle tecnologie impiantistiche sulla qualità del vino. Atti del $6^{\circ}$ Convegno Internazionale Vino e Salute. Palavetro Aeroporto Trapani Birgi, 19-22 maggio 2004.

Arnold R.A., Noble A.C., Singleton V.L. Bitterness and astringency of phenolic fractions in wine. Journal of Agricultural and Food Chemistry, 1980, 28, 675-678.

Catania P., Vallone M., Pipitone F. Analysis of the main factors influencing the quality of wine from mechanically harvested grapes. Journal of Agricultural Engineering. 2009. 4. 27-30.

Castillo-Sanchez J.X., Garcia-Falcon M.S., Garrido J., Martinez-Carballo E., Martins-Dias L.R., Mejuto X.C. Phenolic compounds and colour stability of Vinhao wines: Influence of wine-making protocol and fining agents. Food Chemistry, 2008, 106, 18-26.

Corona O., Asproudi A. Analisi della componente aromatica varietale del vino Nero d'Avola microvinificato in purezza. Atti del $6^{\circ}$ Congresso Italiano di Scienze e Tecnologie degli Alimenti. Cernobbio (Co), 18-19 settembre 2003.

De Rosa T. Tecnologia dei vini rossi. Edizioni AEB Brescia, 1983.

Di Majo D., La Guardia M., Giammanco S., La Neve L., Giammanco $\mathrm{M}$. The antioxidant capacity of red wine in relationship with its polyphenolic constituents. Food Chemistry, 2008, 111, 45-49.

Di Stefano R., Cravero M.C., Gentilini N. Metodi per lo studio dei polifenoli dei vini. L'Enotecnico, 1989, 5, 8389.

EC Regulation 2676/90.

Echeverry C., Ferreira M., Reyes-Parada M., Abin-Carriquiry J.A., Blasina F., Gonzales-Neves G., Dajas F. Changes in antioxidant capacity of Tannat red wines during early maturation. Journal of Food Engineering, 2005, 69, 147-154.

Garcia-Puente Rivas E., Alcalde-Eon C., Santos-Buelga C., Rivas-Gonzalo J.C., Escribano-Bailon M.T. Behaviour and characterization of the colour during red wine mak- ing and maturation. Analytica Chimica Acta, 2006, 563, 215-222.

Gigliotti A. Esperienze di vinificazione con i vinificatori rotanti. Vini d'Italia, 1980, XXII, 126, 3, 143-151.

Gomez-Plaza E., Gil-Munoz R., Lopez-Roca J.M., Martinez-Cutillas A., Fernandez-Fernandez J.I. Maintenance of colour composition of a red wine during storage. Influence of prefermentative practices. maceration time and storage. Labensmittel-Wissenschaft und Technologie, 2002, 35, 46-53.

Netzel M., Strass G., Bitsch I., Könitz R., Christmann M., Bitsch R. Effect of grape processing on selected antioxidant phenolics in red wine. Journal of Food Engineering, 2003, 56, 223-228.

Pérez-Lamela C., García-Falcón M.S., Simal-Gándara J., Orriols-Fernández I. Influence of grape variety, vine system and enological treatments on the colour stability of young red wines. Food Chemistry, 2007, 101, 601-606.

Rakatovao A., Berthonneche C., Guiraud A., De Lorgeril M., Salen P., De Leiris J., Boucher F. Ethanol, wine, and experimental cardioprotection in ischemia/reperfusion: role of the prooxidant/antioxidant balance. Antioxid Redox Signal, 2004, 6 (2), 431-438.

Ribéreau-Gayon P., Dubourdieu D., Donèche B., Lonvaud A. Trattato di enologia I - Microbiologia del vino Vinificazioni. Edagricole, 1998.

Ribéreau-Gayon P., Glories Y., Maujean A., Dubourdieu D. Trattato di enologia II - Chimica del vino - Stabilizzazione - Trattamenti. Edagricole, 1998.

Rice-Evans C.A., Miller N.J., Paganga G. Antioxidant properties of phenolic compounds. Reviews. Trends in Plant Science, 1997, 2, 152-159.

Rieger T. Rotary fermenters in a roll again. Vineyard \& Winery Management, 1999, 9.

Ruf J.C. Overview of epidemiological studies on wine. health and mortality. Drugs Under Experimental and Clinical Research, 2003, 29 (5-6), 173-173.

Somers T.C. The polymeric nature of wine pigment. Phytochemistry, 1971, 10, 2175-2186.

\section{SUMMARY}

The aim of this work is to compare two types of winemaking tanks, horizontal and vertical, using Nero d'Avola grapes, in order to assess the capacity of extraction of phenolic compounds that determine the quality of red wines.

The study shows that in wine made by horizontal winemaking tanks, both anthocyanins and polyphenols have a higher decrease in time compared to wine made by the vertical type.

The higher values of polyphenols found in the horizontal type appear to show that wines produced by this type of winemaking tank have a better quality in terms of health for antimicrobial, antioxidant and antiinflammatory properties of these molecules.

Keywords: winemaking tank, red wine, quality, polyphenols. 